\title{
Modelling sustainability and the role of deliberative democracy
}

\author{
Hartz-Karp, J. and D. Marinova \\ Curtin University Sustainability Policy (CUSP) Institute \\ Email: J.Hartz-Karp@curtin.edu.au
}

\begin{abstract}
Given the strong inertia of preconceived ideas about the role of ordinary citizens, it is not surprising that deliberative democracy has been invisible to most sustainability modellers. If modelling is a way of copying how a system works in real life, then the traditional modelling approaches to sustainability, grounded in particular disciplines, often based on economic rationalism and relatively short-term horizons, will be inadequate. Modelling that is more holistic and resilient (capable of adaptation) will need to include the values and viewpoints of ordinary people, as well as collaborative problem solving, policy development, decision-making, action and continual monitoring.

The paper analyses several case studies which have used deliberative democracy techniques to create models for urban development planning in Western Australia. It concludes that deliberative democracy can provide a different way to the development of models and communities which are not only more sustainable but also more resilient to the unpredictability of the future.
\end{abstract}

Keywords: Dialogue with the City, Perth, Geraldton, planning, Western Australia 


\section{INTRODUCTION}

There has been enormous progress made in the development of modelling tools and systems which facilitate decision making related to sustainability issues. This includes among many others environmental decision and information support tools (McIntosh, 2011), building assessment tools (Beattie, 2011), planning support systems (Geertman and Stillwell, 2003). Despite increasing involvement of stakeholders and policy-makers in the actual processes of modelling and development of such tools (Voinov and Bousquet, 2010; Van Delden et al., 2011), many questions are asked as to what makes such models, tools and information systems useful (e.g. Diez and McIntosh, 2009) as well as how and when they can be included in the decision-making processes (Matthews et al., 2011). Some of these issues can be improved through interactive design which allows for user requirements and needs to be constantly updated and fed into the system (Holtzblatt et al., 2005). However there is also constantly increasing evidence of side effects and unintended consequences that modelling rarely can account for, the most obvious example being the impacts of the fossil fuel based economies on the natural environment.

Many call for a new way of developing and applying models which is not only participatory and transparent but also contributes to the proper representation of the social, economic, policy and environmental context in which policies are formulated (e.g. Bassi, 2009). Todorov and Marinova (2011) in particular argue for a new approach to modelling sustainability that is transdisciplinary, and incorporates not only sustainability information and information flow, but also people's values, understandings and perspectives, elicited in a non-hierarchical environment, where there is full awareness that sustainability cannot be achieved without cooperation. Such cooperation should incorporate understanding and knowledge creation, but also policy formulation, decision-making and governance which in essence describes deliberative democracy.

Described as a response to the perceived inadequacies of the mechanisms of representative democracy that exist and are being used in most western type democracies (Smith and Wales, 2000; Levine, 2003), deliberative democracy is built around "fair and open community deliberation about the merits of competing political arguments" (Uhr, 1988: 4). According to the Deliberative Democracy Consortium (2011: n.p.), a network of practitioners and researchers from more than 50 organisations and universities across the globe: "Deliberation is an approach to decision-making in which citizens consider relevant facts from multiple points of view, converse with one another to think critically about options before them and enlarge their perspectives, opinions and understandings". Deliberative democracy is a way for policy formulation and decision-making that allows for such deliberation to occur as well as to inform and influence future development. According to Hartz-Karp (2005: 2), a component for this new type of governance is the building of "an environment of trust, where open and honest dialogue can develop" which allows for the issues of concern to be reframed so that appropriate solutions can emerge.

\section{DELIBERATIVE DEMOCRACY AND MODELLING}

Deliberative democracy is a mode of shared decision-making involving public deliberation(s) among demographically representative participants, who reason together under conditions that promote mutual respect and understanding, to arrive at a broadly supported, coherent voice, which then influences policy development and decision-making. The principles underlying public deliberation include collaboration, inclusion, egalitarianism, transparency, mutual learning, influence and sustainability. Despite some emerging and powerful examples (e.g. Hartz-Karp, 2005; Edwards et al., 2008; Herriman et al., 2011 in Australia), deliberative democracy has not been integral to sustainability and any policy making for a more sustainable future, let alone sustainability modelling. In part, this is because of our assumptions about the role of researchers, modellers, experts, ordinary citizens, elected officials and technocrats and the democratic process. They are rooted in the neo-classical division of labour and consequent separation of knowledge, power, authority and roles within society:

- Researchers are people who acquire new knowledge through systematic investigation and are capable of analysing complex data and other evidence in order to establish facts. They are the ones who hold most of the new knowledge within society, can best understand emerging trends and need to account for the prevailing ethics within society (Jackson, 2005);

- Experts are people who are reliable as far as their skills and knowledge are concerned as they have a proven track record of competently handling previous similar situations (Rifkin and Martin, 1997). Their opinion can inform elected officials in their decision-making; 
- Modellers are people who create scientific, including computerised, models based on expert and scientific knowledge. These models are used by technocrats to find solutions and implement decisions as well as occasionally by politicians to formulate policies. A good example are Integrated Assessment Models for climate change (http://sedac.ciesin.org/mva/MVAUG/ugwho.html);

- Politicians are elected with a mandate to represent their constituencies based on a majority support for their views and platforms at the time of the election. This mandate extends over their entire term of office, the public exerts its democratic voting rights and by doing so relegates any decision making power leaving it in the hands of what many refer to as metagovernance (e.g. Sorensen, 2006);

- Technocrats are people with specialist training who occupy positions within the bureaucracy because they are good at problem-solving (Njalsson, 2005), particularly when it comes to the application of new technologies, however importantly they do not represent the interests of a specific group within society;

- Ordinary (or lay) citizens, despite being able to use and to a certain extent understand some user-friendly models, generally do not have the information, knowledge, capacity or even the interest to understand expert knowledge and importantly make decisions, particularly when it comes to matters that are complex and with long-term implications (Hartz-Karp and Briand, 2009). They however should be consulted once certain solutions/plans/initiatives are being proposed in order to gauge their acceptance by society, secure their support if accepted and engagement in any eventual implementation. This often is met with significant disinterest and apathy by the general public, described as democratic deficit (Carson, 2008).

Deliberative democracy is not the only field that challenges this worldview (as represented by the above assumptions). Calls for recognising the importance of ordinary people, their skills, knowledge and ability to handle complex problems within a long time framework are coming from areas which are perceived as highly quantitative and scientific, such as the geosciences (Bolman, 2010), to the more broadly accepted community science which predominantly deals with local environmental events and trends. Deliberative democracy takes this further by advocating for collective governance with important problems brought for discussion by ordinary citizens in order to find solutions. Urban and regional planning is of particular interest as it represents all complexities and intricacies of the social, ecological and economic fabrics of society.

Modelling now is a critical element of any planning and is usually seen as the most objective way of understanding the relationship between the present and the future. Since models are created by experts, using the best available data in their field, it is seen to be the best tool for gaining greater understanding of the present and the unpredictable future. However, all fields of knowledge are based on sets of assumptions that illuminate some issues to the detriment of others. We accept this, and in so doing, we often forget how precarious this is - the most recent global financial crisis being a case in point, and yet another, the previously mentioned impacts of the fossil fuel based economies on the natural environment.

One way of reducing the risks of expert driven modelling is to involve the values and perspectives of everyday people, who, given the opportunity to understand the complexity of the issues, can arrive at new perspectives, offering new dimensions. Modelling developed in this way would be more grounded in everyday wisdom, more holistic since it is not predicated upon disciplinary fields, hence more likely to be adaptable to unanticipated consequences, and as a result, more effective. Equally important is the issue of how and when modelling can or should be incorporated in the decision-making process. Introduced too late in this process, in particular after the fact, decision-makers are left with insufficient and often inadequate options. The principles and practices of deliberative democracy highlight the pivotal nature of collaborative governance to any deliberative participation, embedding the aspect of decision-making into planning's fabric.

Both in the general field of sustainability and the specific area of sustainability modelling, discussions involving participation in policy development, including planning, have been focused on the merits of particular techniques used. Notably, in sustainability modelling, the literature dedicated to the issue of involving people has discussed or argued the merits of soft (qualitative) and hard (quantitative, structured) systems dynamic modelling; with some calls to integrate the two. What has been missing is any discourse on the principles underlying inclusive, participative policy development. However, when we investigate the most exciting initiatives in improving democracy (e.g. www.vitalizing-democracy.org/), they all involve a radical redesign that has broken the above assumptions. Indeed, the integration of soft and hard approaches and the blurring of areas of expertise are now vital in developing a more resilient, sustainable community.

Deliberative democracy research has also shown that the assumptions we hold about ordinary citizens and effective governance do not hold. Notably, it has been demonstrated that through public deliberation, citizens arrive at a coherent voice with a clearly explained rationale (Fishkin, 2005); that this coherent voice is based on their conceptions of the common good (Brown, 2006); that such deliberative outcomes result in increased 
accountability and legitimacy of decisions (Benhabib, 1996); that they enhance social justice and effective governance (Fung, 2003); and that there are secondary benefits including improving participants' civic attitudes, and potential influence on public officials' attitudes, behaviours and choices (Gastil, 2009).

The initial focus of deliberative democratic initiatives is on framing the issue to be deliberated, or structuring the problem or opportunity to be explored; then creating 'minipublics' of those representative of the population in order to understand the different values, perspectives and viewpoints, develop or refine the options, weigh the merits of each option, and form a coherent voice about a recommended direction forward. Such deliberations often involve a process incorporating large and small scale, face-to-face and online deliberations, each building on the next. These processes are influential, leading to collaborative policy development and decision-making. They often bring about shifts in participant attitudes and priorities and sometimes transformational change.

To explain how a deliberative democratic process unfolds, several examples are outlined below. The intent is three-fold: firstly, to increase understanding of the underlying principles and practices of deliberative democracy; secondly, to demonstrate how such processes can add value to decision-making; and thirdly, to highlight how modelling was integrated, noting how it could have been utilised more innovatively to push the boundaries of understanding and hence the quality of decision-making. Although each of the initiatives included a variety of modelling exercises, in the main, complex modelling was created by an expert group, including stakeholders and public servants. In one instance, however, in developing a model for online deliberation, an iterative process was applied that effectively involved everyday citizens.

\section{CASE STUDIES IN DELIBERATIVE PLANNING}

\section{Case Study 1: State-wide and City metropolis sustainability planning}

In 2001, the newly elected Western Australian (WA) Government had a platform of freight road-train reform, in particular, preventing large road trains from making further incursions into the metropolitan area as they sought direct routes to the port. The deliberative democracy process that ensued, the Road Train Summit, recommended not only major road train reform but also broader deliberations on the whole State freight network. The Freight Network Review was instigated as a result. The latter deliberative process resulted in not only a wide-ranging freight reform agenda, but also suggested that the values of how we want to live should be deliberated, with the focus on the future sustainability of the Perth metropolis. The Dialogue with the City resulted, aiming at Perth becoming the world's most liveable city. These initiatives (described in www.21stcenturydialogue.com/) illustrate how everyday citizens cut through the silo thinking of policydevelopers and decision-makers, leading to more holistic solutions, critical to sustainability and to modelling.

Each of these processes had a similar set of underlying principles and practices including:

- Creating an equitable process: All perspectives should have equal right to be heard, and each person's comments should be listened to with consideration. A Steering Team was constituted comprising stakeholders and representatives of the range of perspectives on the issue, including protagonists and antagonists as well as scientific and technocratic views, with the task to oversee the process to ensure it was fair, transparent, accountable and maximised opportunities for inclusion, deliberation and influence.

- Achieving inclusiveness and representativeness: Given the charged nature of many issues under consideration, a representation formula was developed to ensure no one group dominated the discussions: 1/3 from an invited random population sample, provided by the WA Electoral Commission; 1/3 from respondents to advertisements in state wide and local newspapers, industry journals, local employment places and community newsletters; and 1/3 from stakeholder groups including government, industry and community groups, with an additional focus on the Indigenous, culturally diverse, young people and disabled.

- Maximising opportunities for deliberation: Participants were purposefully seated at small tables (8-10 per table) to ensure maximum diversity of views. They sat next to someone they didn't know or didn't like or whose views were totally different to theirs. "Group think" was minimised and the potential was enhanced for creating bridging capital, discourse between unconnected others, important to increasing trust and understanding. The agenda of each deliberation was designed to learn from different perspectives, investigate options, weigh each against agreed values, and determine the best way forward. Trained facilitators at each table were tasked to ensure an egalitarian process and maximising the collective intelligence of their group.

- Designing a deliberation technique that fits the purpose at hand: Often, known deliberation techniques were adapted and modified, and new techniques were developed or pioneered (more information at www.thataway.com and www.21stcenturydialogue.com). In each deliberative process, lasting over several years, a series of large and small scale public deliberations, both online and face-to face, were integrated with 
social media and partnerships with mass media, each initiative building on the other in order to arrive at a coherent voice of prioritised recommendations that had been developed by large numbers of participants, representative of the population demographics and attitudes. Modelling was integral to each initiative. These included a combination of soft approaches that assumed the problem itself was problematic and required in depth dialogue and carefully considered deliberation, as well as hard approaches such as Multi Criteria Analysis Consensus Conference, various decision-making models, and more integrated approaches such as a $21^{\text {st }}$ Century Town Hall Meeting; a GIS based city and regional planning game and online deliberation.

- Maximising influence: This was a critical element of the process, achieved by the Minister's public commitment to the extent of influence of the deliberation process prior to and throughout the deliberative process. The Minister highlighted at each forum that her objective was to place the community at the heart of the decision-making process. She also input to and signed-off on the representativeness and deliberativeness of each process. Senior officials participated throughout each deliberation event as part of the support team. This included the Minister and her government agency CEOs and Executive Teams involved in the issue at hand. Each process concluded with broad based Implementation Teams, with deliberation participants as key members, tasked with devising implementation plans based on the outcomes of the deliberations, and ensuring participants and the broader community regularly received implementation progress updates, as well as continued opportunities for input. Each of these elements reinforced the intent of each public deliberation to influence policy development, decision-making and resulting action.

- Enhancing sustainability outcomes: It is often the case that highly emotive, contentious issues result in an impasse, usually a 'win/lose' situation, with the community often perceiving themselves to be the losers. In each of the public deliberations described in Case 1, while divisive, sometimes polemic debate characterised their start, they concluded with jointly owned directions forward that united industry, government and community. In each instance, the public deliberations had cut through the silo thinking of technocrats, academics and single-minded advocates to arrive at broad ranging recommendations that were more farsighted, holistic and communitarian than the Minister could have made without their support. These included the State influencing the national road train regulation, a reorganisation of the Main Roads Department to deal with the new agenda; dramatically shifting the focus from road to rail and shipping in the freight network review; and flying in the face of continued housing sprawl to not only recommend but publicly stand up for their agreed plan of a Network City aimed at future sustainability, which was being hammered by vested interests and the media. For numbers of participants, their engagement had been transformative, with their publicly stated disinterest in public issues changing to intense civic pride and participation in planning for the future. Below is a comment form Fleay (2006: 8), a WA renowned author, scientist and futurist:

The pioneering work on all-inclusive community and stakeholder dialogue to find solutions to complex problems as used in the Department of Planning and Infrastructure in Western Australia gives a lead that needs extending and developing everywhere... Developed further, this pioneering approach can be a powerful tool for coping with the changes arising from declining oil supply, indeed the only way.

\section{Case Study 2: 'Geraldton 2029 and Beyond'}

Although the principles and practices underlying deliberative democracy have been similarly undertaken in the Geraldton process, there have been some significant additions. It was determined at the outset that this would be a 4-year process, a joint commitment between the City-Region and Curtin University Sustainability Policy (CUSP) Institute to apply and evaluate deliberative democracy as a means to improve sustainability. It continues to be a two-pronged initiative, on the one hand creating a deliberative community, capable and willing to collaboratively resolve the big issues facing the City-Region, and on the other hand, to pioneer different forms of collaborative governance to try to find ways of institutionalising the practice and intent of deliberative democracy. A broad array of public deliberation techniques was applied (more information on www.vitalizing-democracy.org). Some of these techniques relied upon modelling, with the model being developed and applied by a team of experts, including stakeholders and public servants. In its second year, the process included a series of Enquiry-By-Design processes, integrating hard and soft modelling, that have been adapted to be more participative and influential that the usual model.

However, one modelling initiative applied in Geraldton 2029 and Beyond, also integrating hard and soft modelling, involved everyday people in its development and implementation. This is the iterative development of a model of online deliberation that aims to be deliberative, sustainable, largely self-managed, inclusive and influential. The online software is called CivicEvolution (www.civicevolution.org or www.2029andbeyond.com.au). Over a period of several years, this software evolved to include a selfmanaged online deliberation that enables ordinary citizens to move from ideas to jointly created proposals, incorporating social media and various gaming methods to encourage participation and success. In each instance, online deliberators have been invited to outline problems experienced with the model, to suggest 
improvements and experiment with new models. The online deliberation model has radically changed since its inception, and is leading the way in developing self-managed, online deliberation that enhances the likelihood of influence and action. In our view, the principles underlying both forms of participation have something to teach modellers. By utilising the wisdom of a broad range of people, not necessarily just those experts who usually frame and create models, it is possible that we might create models that have a greater likelihood of taking into account of the unanticipated consequences of systems in a chaotic environment.

\section{CONCLUSION}

Given the strong inertia of preconceived ideas about the role of ordinary citizens, it is not surprising that deliberative democracy has been invisible to most sustainability modellers. If modelling is a way of copying how a system works in real life, then the traditional modelling approaches to sustainability, grounded in particular disciplines, often based on economic rationalism and relatively short-term horizons, will be inadequate. Modelling that is more holistic and resilient (capable of adaptation) will need to include the values and viewpoints of ordinary people, as well as collaborative problem solving, policy development, decision-making, action and continual monitoring. Deliberative democracy can provide a lot of this.

Scientists have suggested that improving sustainability will require not just technological fixes but social and organisational adaptive responses that depend on new ways of behaving, discussing and problem solving (IPCC, 2007). Modelling is an integral aspect of this process, especially given its influence on our preparedness for the future. However, as long as modelling only engages experts and sometimes invited stakeholders, it is unlikely that the taken-for-granted assumptions of that particular worldview will be seriously challenged. To enable transformational change, we will need to find new ways of developing models to include those who think sufficiently differently to test our assumptions and help us create new paradigms. The most obvious way to do this is to include everyday citizens, preferably randomly sampled to avoid bias. In so doing, modelling experts would need to assume that if everyday citizens have sufficient information, time and opportunity to deliberate, they will add a dimension to the modelling effort that is based on the community's values and everyday wisdom.

In addition, we will need to pioneer new ways of policy development and decision-making that is sufficiently early in the process and robust that traditional power relations are challenged and more adaptive management could result. To do this in a way that has the possibility of being transformative, we need to find new ways of collaborative governance and where feasible, to institutionalize them so they become part of everyday practice rather than the exception. Deliberative democracy offers us a potential way forward. Experience of scores of deliberative democracy initiatives have demonstrated that this is not mere wishful thinking. Such deliberative processes have included everyday citizens in each step of the process and in so doing, participant views have invariably shifted to greater sustainability. This has invariably resulted in more holistic solutions than those developed by our silo driven mechanisms of governance. These comprehensive solutions have given the decision-makers the legitimacy to break through barriers of their limited control or influence, to form new alliances and implement decisions that matter.

\section{ACKNOWLEDGMENT}

The authors want to acknowledge the financial support of the Australian Research Council.

\section{REFERENCES}

Bassi, A.M. (2009). Analyzing the role of integrated, dynamic, national development planning models to support policy formulation and evaluation. $3^{\text {rd }}$ OECD World Forum on Statistics, Knowledge and Policy, Busan, Korea. http://www.cepal.org/ilpes/noticias/paginas/2/40352/Bassi_SistemasDinamicos.pdf.

Benhabib, S. (1996). Toward a deliberative model of democratic legitimacy, pp. 67-94. In S. Benhabib (Ed.) Democracy and Difference: Contesting the Boundaries of the Political. Princeton University Press, Princeton.

Beattie, C. (2011). A carbon assessment and design tool to assist in planning low carbon development. MODSIM 2011 International Congress on Modelling and Simulation, Modelling and Simulation Society of Australia and New Zealand, Perth, Australia (this issue).

Bolman, J.R. (2010). Native geosciences: Pathways to traditional knowledge in modern research and education. American Geophysical Union, Fall Meeting, San Francisco CA.

Brown, M. (2006). Survey article: Citizen panels and the concept of representation. Journal of Political Philosophy, 14 (2), 203-225.

Carson, L. (2008). Creating democratic surplus through Citizens' Assemblies. Journal of Public Deliberation 
4(1) Article 5. http://services.bepress.com/cgi/viewcontent.cgi?article=1070\&context=jpd.

Deliberative Democracy Consortium (2011). Deliberative Democracy Net. http://www.deliberativedemocracy.net/index.php?option=com_content\&view $=$ article\&id=19\&Itemid=57.

Diez, E., and McIntosh, B.S. (2009). A review of the factors which influence the use and usefulness of information systems. Environmental Modelling and Software 24:588-602.

Edwards, P.B., Hindmarsh, R., Mercer, H., Bond, M., and .Rowland, A. (2008). A three-stage evaluation of a deliberative event on climate change and transforming energy. Journal of Public Deliberation, 4(1), article 6. http://services.bepress.com/jpd/vol4/iss1/art6/.

Fishkin, J. (2009). When the People Speak: Deliberative Democracy and Public Consultation. Oxford University Press, Oxford.

Fleay, B. (2006). Submission to the Inquiry into Australia's future oil supply and alternative transport fuels. Senate Rural and Regional Affairs and Transport Committee, Canberra. http://www.aspoaustralia.org.au/References/Senate-ASPO/fleaysupp.pdf.

Fung, A. (2003). Recipes for public spheres: Eight institutional design choices and their consequences. Journal of Political Philosophy, 11(3), 338-367.

Gastil, J. (2009). A comprehensive approach to evaluating deliberative public engagement, pp. 15-27. In MASS LBP (Ed.) Engaging with Impact: Targets and Indicators for Successful Community Engagement by Ontario's Local Health Integration Networks. MASS LBP, Toronto, Ontario.

Geertman, S., and Stillwell, J. (2003). Planning Support Systems in Practice. Springer, Berlin-HeidelbergNew York.

Hartz-Karp, J. (2005). A case study in deliberative democracy: Dialogue with the city. Journal of Public Deliberation, 1(1), article 6. http://services.bepress.com/cgi/viewcontent.cgi?article=1002\& context=jpd.

Hartz-Karp, J., and Briand, M. (2009). Institutionalizing deliberative democracy. Journal of Public Affairs, $10(1), 125-141$.

Herriman, J., Atherton, A., and Vecellio, L. (2011). The Australian experience of world wide views on global warming: The first global deliberation process. Journal of Public Deliberation, 7(1), article 3. http://services.bepress.com/jpd/vol7/iss1/art3.

Holtzblatt, K., Burns Wendell, J., and Wood, S. (2005). Rapid Contextual Design, A How-To Guide to Key Techniques for User-Centred Design. Morgan Kaufman, San Francisco CA.

Intergovernmental Panel on Climate Change (IPCC). Summary for Policymakers. In Climate Change 2007: The Physical Science Basis. Cambridge University Press, Cambridge.

Jackson, S.A. (2005). The nexus: Where science meets society. Science, 310, 1634-1639.

Levine, P. (2003). The New Progressive Era: Toward a Fair and Deliberative Democracy. Rowman \& Littlefield, Lanham MD.

Matthews, K.B., Rivington, M., Blackstock, K., McGrum, G., Buchan, K., and Miller, D.G. (2011). Raising the bar? The challenges of evaluating the outcomes of environmental modelling and software. Environmental Modelling and Software, 26, 247-257.

McIntosh, B. (2011). Evaluation of environmental decision and information support tools: from adoption to outcome. MODSIM 2011 International Congress on Modelling and Simulation, Modelling and Simulation Society of Australia and New Zealand, Perth, Australia (this issue).

Njalsson, G.K.A. (2005). From autonomous to socially conceived technology: Toward a causal, intentional and systematic analysis of interests and elites in public technology policy. Theoria: A journal of political theory, 108, 56-81.

Rifkin, W.D., and Martin, B. (1997). Negotiating expert status: who gets taken seriously. IEEE Technology and Society Magazine, (Spring), 30-39. http://www.bmartin.cc/pubs/97ieeets.pdf.

Smith, G., and Wales, C. (2000). Citizens' juries and deliberative democracy. Political Studies, 48, 51-65.

Sorensen, E. (2006). Metagovernance: The changing role of politicians in processes of democratic governance. The American Review of Public Administration, 36(1), 98-114.

Todorov, V., and Marinova, D. (2011). Modelling sustainability. Mathematics and Computers in Simulation, 81(7), 1397-1408.

Uhr, J. (1998). Deliberative Democracy in Australia: The Changing Place of Parliament. Cambridge University Press, Cambridge MA.

Van Delden, H., Seppelt, R., White, R., and Jakeman, T. (2011). A methodology for the design and development of integrated models for policy support. Environmental Modelling and Software, 26, 266279.

Voinov, A., and Bousquet, F. (2010). Modelling with stakeholders. Environmental Modelling and Software, $25,1268-1281$. 